\title{
Controlling the anodizing conditions in preparation of an nanoporous anodic aluminium oxide template
}

\author{
Azadeh Nazemi*, Seyed Abolfazl Seyed Sadjadi \\ Department of Chemistry, Iran University of Science and Technology, Tehran, Iran
}

\begin{abstract}
Porous anodic aluminium oxide (AAO) template is commonly used in the synthesis of one-dimensional nanostructures, such as nanowires and nanorods, due to its simple fabrication process. Controlling the anodizing conditions is important because of their direct influence on the size of AAO template pores; it affects the size of nanostructures that are fabricated in AAO template. In present study, several alumina templates were fabricated by a two-step electrochemical anodization in different conditions, such as the time of first process, its voltage, and electrolyte concentration. The effect of these factors on pore diameters of AAO templates was investigated using scanning electron microscopy (SEM).
\end{abstract}

Keywords: porous anodic aluminium oxide; two-step anodization; nanostructures; scanning electron microscopy

(C) Wroclaw University of Technology.

\section{Introduction}

One-dimensional nanostructures, such as nanowires and nanorods, have been a "hot topic" in recent years, due to their unique mechanical [1], electrical [2-4], optical [5-9], thermo-electrical [10-13], and magnetic [14-17] properties, which differ extensively from the bulk structures [18]. However, the morphology and the size distribution of the nanoscale materials are the most important factors affecting their physical properties [19]. Nanoscale porous surfaces are extensively demanded for both nanoscience and nanotechnology as templates [20], for the synthesis of metallic alloy, oxide and semiconductor one-dimensional nanostructures [21-25]. One-dimensional nanostructures, employing the AAO template, are very attractive for various applications [26-29]. An AAO template is a closepacked array of hexagonal parallel and cylindrical cells with a pore in the center of each cell [30]. Due to their high repeatability and high quality of structures, AAO templates have been widely used in producing well-ordered one-dimensional nanostructures [31]. A common preparation

*E-mail: nzm_azadeh@yahoo.com method of AAO template is two-step anodization process, suggested by Masuda and Fukuda in 1995 [32]. The two-step anodization on aluminium foil at a constant voltage provides a well-ordered shape compared to one-step anodization [33]. The morphology and diameter of the pores can be controlled via altering the anodization conditions and electrolyte type [34]. In the current investigation, one purpose was to study: the effect of the anodization time at the first-step of the process on the size of the pores. In the next step, three templates were prepared in the same conditions at different voltages in order to investigate the effect of anodizing voltage on the diameter of the AAO templates. In addition, three AAO templates were fabricated to explore the influence of electrolyte concentration, while other conditions, including voltage, temperature, and anodizing time, were kept constant. In this study, the prepared AAO samples were investigated with SEM.

\section{Experimental}

A porous anodic aluminium oxide template was prepared by anodizing high purity (99.9\%) aluminium film in oxalic acid solution as an electrolyte. Prior to anodizing, aluminium sheets were 


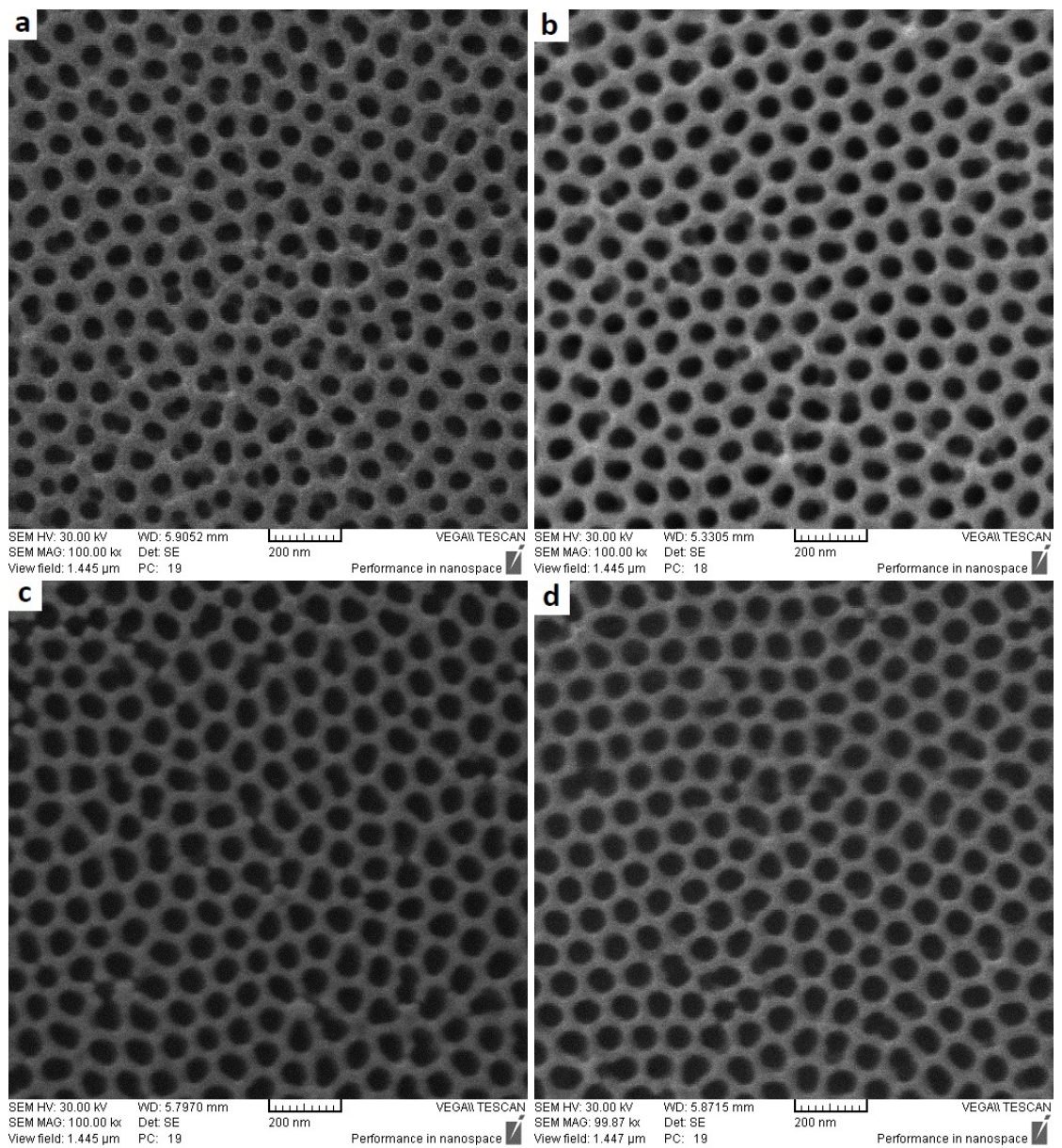

Fig. 1. SEM images of AAO templates. The first anodization was carried out for: (a) $2 \mathrm{~h}$, (b) $5 \mathrm{~h}$, (c) $10 \mathrm{~h}$, (d) $20 \mathrm{~h}$.

annealed at $500{ }^{\circ} \mathrm{C}$ for 10 hours in order to decrease the defects in the aluminium films and remove the mechanical stress on the surface. After that aluminium films were degreased ultrasonically with acetone for 10 minutes. The films were put into $1 \mathrm{~mol} / \mathrm{L} \mathrm{NaOH}$ for 3 minutes to remove the natural oxide on the aluminium film. After washing the samples with deionized water they were polished in a $1: 4$ volume mixture of $\mathrm{HClO}_{4}$ (60 wt.\%) and $\mathrm{C}_{2} \mathrm{H}_{5} \mathrm{OH}$ (96 wt.\%), and the applied voltage was $20 \mathrm{~V}$. Keeping the operational temperature low was important in this process since the electropolishing reaction was extremely exothermic. Therefore, the temperature was maintained at $3{ }^{\circ} \mathrm{C}$ during the electropolishing. In order to investigate the effect of the time of first anodization on the pore diameters, four samples were prepared in different times in $0.3 \mathrm{M}$ oxalic acid solution at $40 \mathrm{~V}$. Other samples were produced at different voltages at the same anodizing concentration, and three samples were prepared at various oxalic acid concentrations at a constant voltage of $40 \mathrm{~V}$. All the samples prepared for investigating both voltage and concentration effects were anodized for 20 hours, while the anodizing temperature was kept constant at $6{ }^{\circ} \mathrm{C}$. After the first anodization, to remove the oxide layer, the samples were immersed into a mixture of 6 wt. $\% \mathrm{H}_{3} \mathrm{PO}_{4}$ and 1.8 wt. $\% \mathrm{H}_{2} \mathrm{CrO}_{4}$ at $70{ }^{\circ} \mathrm{C}$ for 3 hours. The second anodizing process was carried out in similar conditions with the time of first anodization of 1 hour. After the second anodization, all samples were etched in $\mathrm{CuCl}_{2}(80 \mathrm{~g} / \mathrm{L})$ for 30 minutes to obtain free alumina membranes. Subsequently, the AAO templates were immersed into 
a $5 \% \mathrm{H}_{3} \mathrm{PO}_{4}$ solution for 40 minutes, at room temperature, in order to widen the channels.

\section{Results and discussion}

\subsection{Effect of the time of first anodization on the pore diameter}

In order to study the effect of the time of first anodization, four AAO templates were prepared in different times of first anodization $(2,5,10$ and 20 hours) at a constant voltage of $40 \mathrm{~V}$, in a solution containing $0.3 \mathrm{M}$ oxalic acid at $6{ }^{\circ} \mathrm{C}$. Fig. 1 presents the SEM images of AAO samples; it can be seen that increasing the time of the first anodization did not significantly change the size of pores. This observation could be proved by drawing a diagram of pore diameter averages versus the time of first anodization. Fig. 2 shows the changes in pore diameter as a result of increasing the first anodization time; the diagram was changed slightly by an upward slope and it is nearly a straight line. This diagram implies that the time of first anodization has not influenced the size of pores; however, comparing the SEM images (Fig. 1) it was found that the cells became more ordered as a result of increasing the first anodization time.

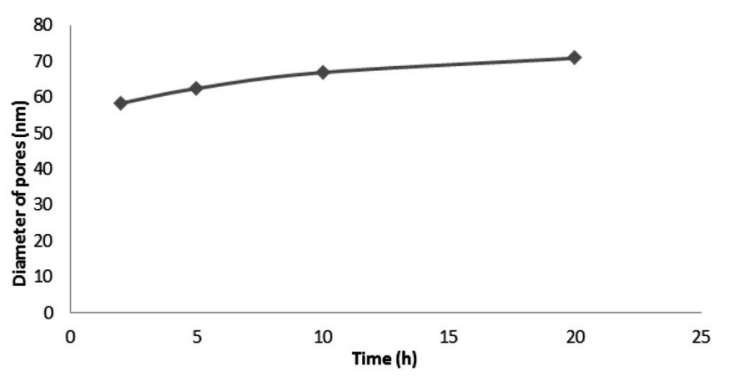

Fig. 2. Diagram of pores diameter change versus the time of first anodization.

\subsection{Effect of anodizing voltage on pore diameters}

Anodization of high purity aluminium films electrochemically is a usual technique for preparing AAO templates. In this study, the samples of pretreated aluminium were anodized in $0.3 \mathrm{M}$ oxalic acid at different voltages. Fig. 3 shows the
SEM images of the AAO templates obtained under constant voltages of $30,40,50 \mathrm{~V}$, respectively. It can be seen clearly that the diameters of the pores were enhanced by increasing the applied voltage. The higher voltage leads to strengthening of the electric field. As a result of a stronger electric field, dissolution of the oxide layer is increased. In addition, the cell walls become thinner; in other words, the diameter of the pores increases.

Fig. 4 shows the diagram of the pore diameter $(\mathrm{nm})$ versus voltage $(\mathrm{V})$ displaying an upward slope. In Fig. $3 c$ it is presented the image of an AAO template that was fabricated at $50 \mathrm{~V}$. This picture shows the effect of high voltage on destroying the structure of the AAO template at high anodizing voltage. As it can be seen, in the most of the sites the cell walls were broken or they were nearly to break. Breaking the cell walls and joining the adjacent cells increased the size of the pores, while reducing the pores density. This kind of structure (Fig. 3c) is not desirable for synthesizing one-dimensional nanostructures since it does not present a uniform structure; the size of the pores is too big in comparison with the samples, which were obtained under 30 or $40 \mathrm{~V}$ (Fig. 3a, b). Actually, high quality physical properties are not achievable with this size of the pores and non-uniform structure (Fig. 3c).

\subsection{AAO template obtained at different electrolyte concentrations}

The first anodization is a critical step since the structure of the AAO template and the size of the pores directly depend on it. The diameter of the pores can be determined by changing the concentration of anodizing solution. The purpose of this study was investigating the size of the pores of AAO templates. Electrolyte concentration, as a key factor, should be controlled during the anodization. Fig. 5 presents SEM images of the AAO templates that were anodized in $0.2,0.3$ and $0.4 \mathrm{M}$ oxalic acid solutions under a constant voltage of $40 \mathrm{~V}$. It can be seen that the pore size is decreased with increasing the electrolyte concentration (Fig. 5). This reduction is shown in Fig. 6 that shows the diameter changes with respect to different electrolyte 


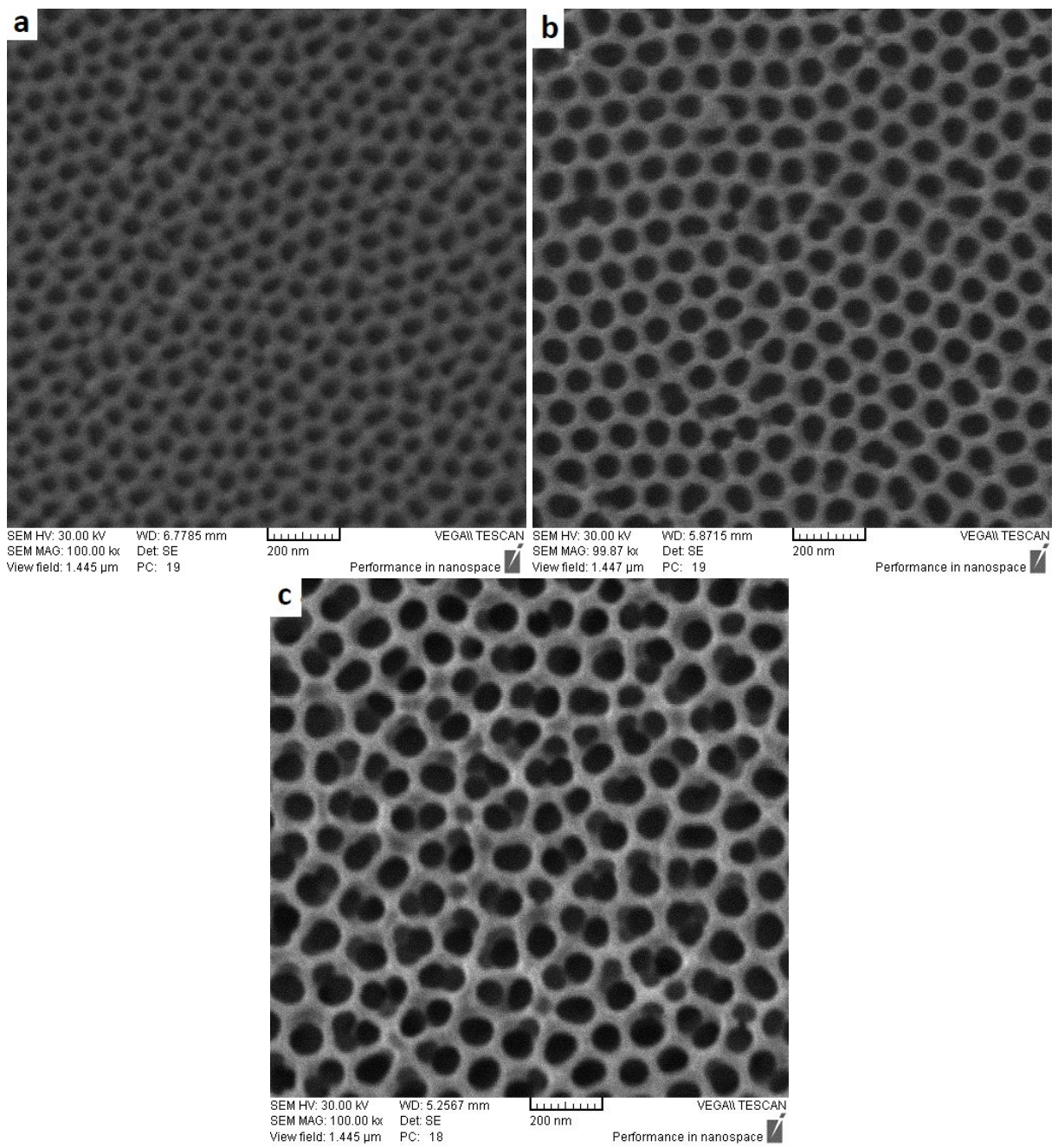

Fig. 3. SEM images of AAO templates obtained at different voltages, (a) $30 \mathrm{~V}$, (b) $40 \mathrm{~V}$, (c) $50 \mathrm{~V}$.

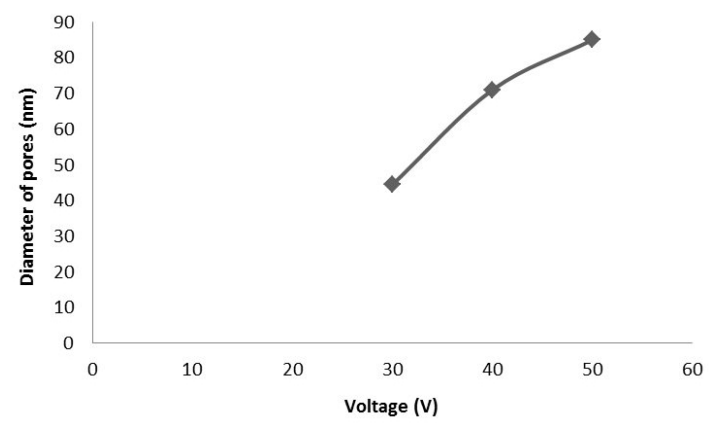

Fig. 4. Diagram of pores diameter versus anodizing voltage.

concentrations. In this situation, higher acid concentration increases the oxidation in comparison to dissolution, so the pore diameter decreases during the anodization.

\section{Conclusions}

To obtain AAO template with uniform structure, two-step anodization of the high purity aluminium films could be the first choice. For preparing desirable AAO templates, anodizing conditions, such as time, voltage and electrolyte concentrations, must be controlled carefully, as for the same samples their pore diameters can be changes in the range of 40 to $80 \mathrm{~nm}$. The results obtained for various samples showed that the pore diameter sizes are directly proportional to the applied 


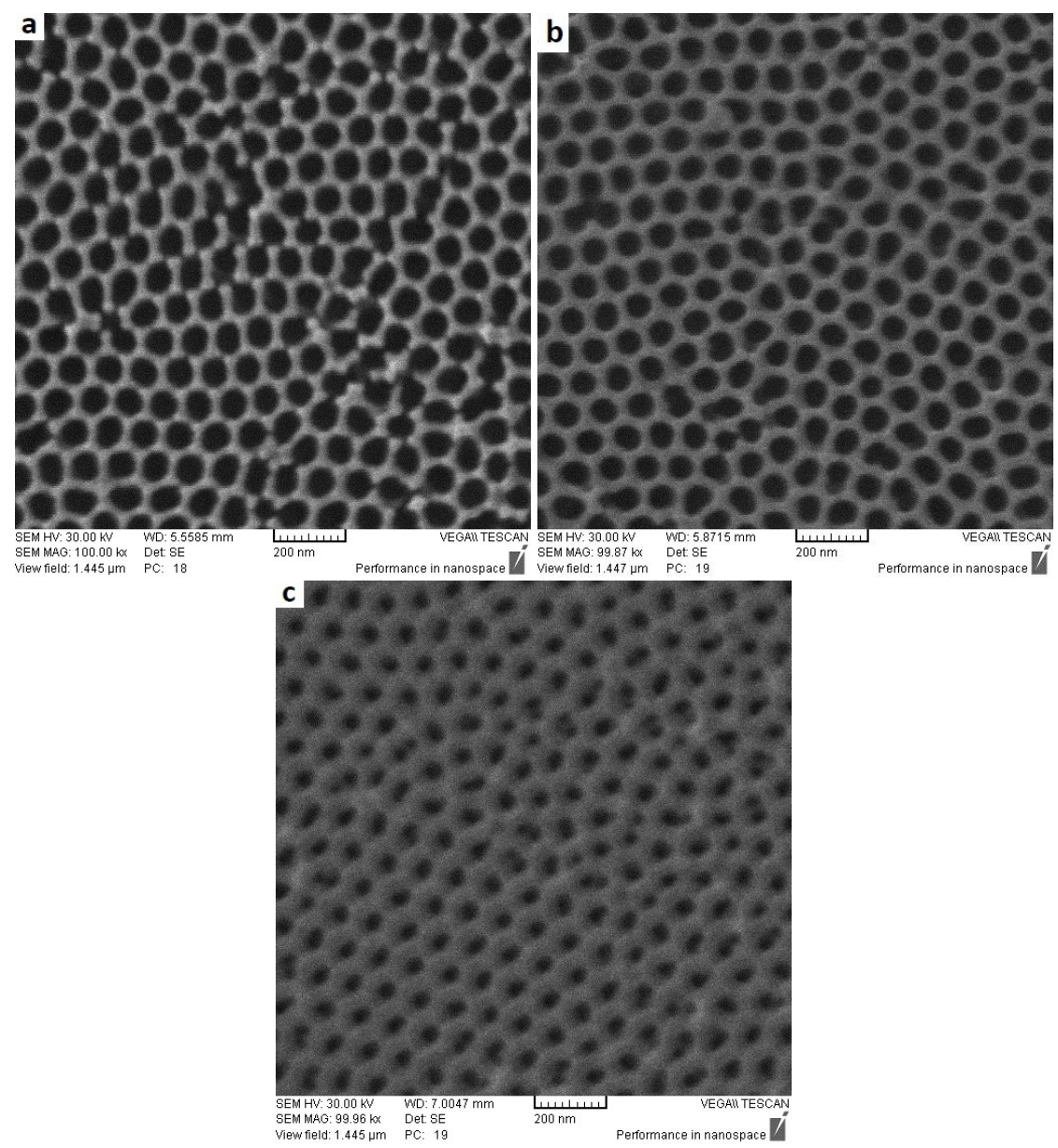

Fig. 5. SEM images of AAO templates obtained at different electrolyte concentrations, (a) $0.2 \mathrm{M}$, (b) $0.3 \mathrm{M}$, (c) $0.4 \mathrm{M}$.

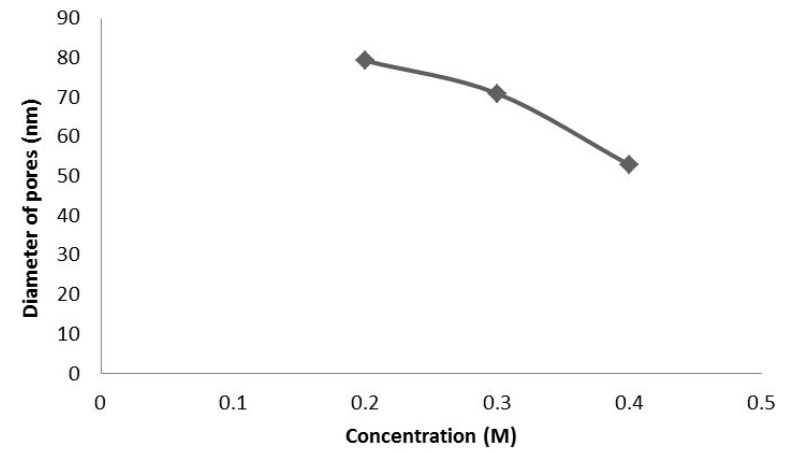

Fig. 6. Diagram of pores diameter of versus electrolyte concentration.

voltage. The current survey proved that an increase in anodization time makes the structure more uniform, while it does not have a significant impact on the size of pores. Moreover, electrolyte concentration can affect the size of pores, as well. By increasing the electrolyte concentration the size of pores has decreased.

\section{References}

[1] Li X., Ling X., Sun L., Liu L., Zeng D., Zheng Q., Compos. Part B-Eng., 43 (2012), 70.

[2] Zhang J.M., Wang X.-C., Zhang Y., XU K.W., Comput. Theor. Chem., 963 (2011), 273.

[3] Wedekind S., Donati F., OKa H., Rodary G., SAnder D., Kirschner J., Surf. Sci., 606 (2012), 1577.

[4] Chen H., Shi D., Qi J., Jia J., Wang B., Phys. Lett. A, 373 (2009), 371.

[5] Ma C., Zhu L., Chen S., Zhao Y., Mater. Lett., 108 (2013), 114.

[6] Yousefi R., Jamali-Sheini F., Khorsand ZaK A., AZARAng M., Ceram. Int., 39 (2013), 5191. 
[7] Chen J., Wang Y., Deng Y., J. Alloy. Compd., 552 (2013), 65.

[8] Sáaedi A., Yousefi R., Jamali-Sheini F., CherAGHizade M., Khorsand ZaK A., Huang N.M., Superlattice. Microst., 61 (2013), 91.

[9] Hadia N.M. A., Mohamed H.A., J. Alloy. Compd., 547 (2013), 63.

[10] Yu C., Zhang X., Leng M., Shaga A., LiU D., Chen F., Wang C., J. Alloy. Compd., 570 (2013), 86.

[11] Yuan G., Li Y., Bao N., Miao J., Ge C., Wang Y., Mater. Chem. Phys., 143 (2014), 587.

[12] Tan X. J., LiU H. J., Wei J., Shi J., Tang X. F., UHER C., Carbon, 53 (2013), 286.

[13] LiU Y.B., Zhou S.M., Yuan X.Y., Lou S.Y., GaO T., SHI X.J., WU X.P., Mater. Lett., 84 (2012), 116.

[14] Maleak N., Potpattanapol P., Bao N.N., Ding J., Wongkokuo W., TAng I. M., Thongmee S., J. Magn. Magn. Mater., 354 (2014), 262.

[15] MA X., Thin Solid Films, 520 (2012), 5752.

[16] Ramulu T.S., Venu R., Anandakumar S., Rani V.S., Yoon S.S., KIM C.G., Thin Solid Films, 520 (2012), 5508.

[17] Senthilkumaar S., Thamiz Selvi R., Ganapathy Subramaniam N., Kang T.W., Superlattice. Microst., 51 (2012), 73.

[18] Garabagiu S., Mihailescu G., Mater. Lett., 65 (2011), 1648.

[19] Zhang J., Kielbasa J.E., Carroll D.L., Mater. Chem. Phys., 122 (2010), 295.

[20] Manzano C.V., Martín J., Martín-GonzÁlez M.S., Micropor. Mesopor. Mat., 184 (2014), 177.

[21] Wang H.J., Zou C.W., Yang B., LU H.B., Tian C.X., YANG H.J., Li M., LiU C.S., FU C.S., LiU J.R., Electrochem. Commun., 11 (2009), 2019.
[22] Ishrat S., MaAz K., Joon LeE K., Jung M.H., KiM G.H., J. Solid State Chem., 199 (2013), 160.

[23] Saedi A., Ghorbani M., Mater. Chem. Phys., 91 (2005), 417.

[24] Ju H., Lee J. K., LeE J., LeE J., Curr. Appl. Phys., 12 (2012), 60

[25] Chang M., Cao X.L., Xu X.J., Zhang L., Phys. Lett. A, 372 (2008), 273.

[26] Xu D., Xu Y., Chen D., Guo G., Gui L., Tang Y., Chem. Phys. Lett., 325 (2000), 340.

[27] Thongmee S., Pang H.L., Ding J., Lin J.Y., J. Magn. Magn. Mater., 321 (2009), 2712.

[28] Yang W., Wu Z., Lu Z., Yang X., Song L., Microelectron. Eng., 83 (2006), 1971.

[29] Fu J., Cherevko S., Chung C.H., Electrochem. Commun., 10 (2008), 514.

[30] Peng X.S., Meng G.W., Zhang J., Wang X.F., ZhaO L.X., WANG Y.W., Zhang L.D., Mater. Res. Bull., 37 (2002), 1369.

[31] Michalska-Domańska M., Norek M., STPNIOWSKI W.J., Budner B., Electrochim. Acta, 105 (2013), 424.

[32] Masuda H., Fukuda K., Science, 268 (1995), 1466.

[33] Chung C.K., Liao M.W., Chang H.C., LeE C.T., Thin Solid Films, 520 (2011), 1554.

[34] Belwalkar A., Grasing E., Geertruyden van W., Huang Z., MisioleK W.Z., J. Membrane Sci., 319 (2008), 192.
Received 2014-04-05 Accepted 2014-06-12 